\title{
Sobre la aplicabilidad del grupo B del artículo 76 del Texto Refundido del Estatuto Básico del Empleado Público como grupo de clasificación profesional del personal funcionario de carrera en las Administraciones Públicas con especial referencia a las Administraciones Locales
}

\section{About the applicability of B group of article 76 of the Consolidated Text of the Basic Statute of Public Employees as a professional classification group of career staff personnel in Public Administrations, with special reference in Local Administrations}

Agustín Juan Gil Franco Universidad Rey Juan Carlos agustinjuan.gil@urjc.es

\section{NOTA BIOGRÁFICA}

Doctor en Derecho. Funcionario de carrera grupo A1. Director General de RR.HH. Ayuntamiento de Alcorcón. Profesor asociado de Derecho Administrativo de las Universidades Carlos III de Madrid, Politécnica de Madrid y de la Universidad Rey Juan Carlos.

\section{RESUMEN}

La creación del grupo B en 2007 por el EBEP como grupo de clasificación de los cuerpos/escalas y categorías de funcionarios para los que se exige como requisito de acceso la posesión de la titulación de «Técnico superior en formación profesional» no ha venido acompañada precisamente por una regulación legislativa o normativa de desarrollo del mismo, pese a las evidentes presiones de algunas categorías profesionales, a la espera de un ámbito propio de promoción profesional y de las propias centrales sindicales. Los Ayuntamientos son los que más directamente ha sufrido esta inacción del legislador pero poseen herramientas para afrontar el reto.

\section{PALABRAS CLAVE}

Grupo de clasificación; cuerpos/escalas y categorías de funcionarios; titulación académica; autonomía local; legislación de función pública.

\begin{abstract}
The creation of the group «B» in 2007 by the EBEP as a classification group for the corps/scales and categories of staff-for which a requirement of access to the certification of «Higher technician in professional training" is required- actually has not been accompanied by a legislative regulation of its development in spite of the evidences of some professional categories, attending an own scope of professional promotion and of the own union companies. The City Councils are the ones which have suffered the most from this inaction of the legislator. Anyway, they have the tools to face the challenge.
\end{abstract}

\section{KEYWORDS}

Group of classification; corps/scales and categories of officials; academic degree; local autonomy; public function legislation. 
REALA. Nueva Época - N. 10, Octubre 2018 - ISSN: 1989-8975 - DOI: 10.24965/reala.v0i10.10514 - [Págs. 96-108]

Sobre la aplicabilidad del grupo B del artículo 76 del Texto Refundido del Estatuto Básico del Empleado Público como grupo de ...

Agustín Juan Gil Franco

\section{SUMARIO}

I. INTRODUCCIÓN. II. LA CREACIÓN DE GRUPOS DE CLASIFICACIÓN PARA LOS CUERPOS, ESCALAS Y CATEGORÍA DE FUNCIONARIOS. III. EL NUEVO GRUPO B DE CLASIFICACIÓN DE CUERPOS, ESCALAS Y CATEGORÍAS EN LA LEGISLACIÓN DEL ESTATUTO DE LOS FUNCIONARIOS. IV. POTESTAD DE LAS ADMINISTRACIONES LOCALES PARA LA CREACIÓN DE CATEGORÍAS PROPIAS DE FUNCIONARIOS DENTRO DEL SISTEMA DE FUNCIÓN PÚBLICA LOCAL. V. EL GRUPO B COMO GRUPO DE CLASIFICACIÓN DE LOS FUNCIONARIOS PROPIOS DE LAS ADMINISTRACIONES LOCALES. VI. CONCLUSIONES. VII. BIBLIOGRAFÍA.

\section{INTRODUCCIÓN}

No ha sido raro que hayan llegado a los gestores de recursos humanos solicitudes de ciertos funcionarios, normalmente de categorías incluidas dentro de sectores especiales de la función pública, que directamente han solicitado su integración en el «nuevo» grupo B, creado y definido en el artículo 76 del Estatuto Básico del Empleado Público, primero, y después en el Texto Refundido (en adelante TREBEP). Basan su petición bien en la posesión de una determinada titulación coincidente con la exigible para el ingreso en dicho grupo, bien, por desarrollar el cuerpo/escala de pertenencia o la categoría funcionarial, servicios para los que se exigía una cualificación profesional determinada. A ello, se han añadido reivindicaciones de carácter sindical en las distintas Mesas de negociación existentes en estas mismas Administraciones públicas, sobre todo, en las locales.

Incluso algunos informes y dictámenes de órganos directivos de función pública han llegado a la conclusión de la imposibilidad de aplicación, -en especial en el ámbito local-, del grupo B como sistema de creación, ordenación y adscripción de cuerpos, escalas y categorías funcionariales al mismo, mientras una disposición legislativa no regulara más en concreto dichas adscripciones.

\section{LA CREACIÓN DE GRUPOS DE CLASIFICACIÓN PARA LOS CUERPOS, ESCALAS Y CATEGORÍA DE FUNCIONARIOS}

El antecedente más directo del artículo 25 de la Ley 30/1984, de 2 de agosto que introducía los grupos de clasificación de los distintos cuerpos/escalas y categorías, fue el Real Decreto-ley 22/1977, de 30 de marzo, de reforma de la legislación sobre funcionarios de la Administración Civil del Estado que, precisamente desde la titulación académica de ingreso exigible para el acceso a Cuerpos, Escalas o Plazas de la Administración Civil del Estado, establecía los denominados «índices de proporcionalidad» correspondientes a cada titulación por orden de grado académico: desde la educación universitaria superior hasta la máxima inferior ${ }^{1}$. La traslación mimética entre uno y otro sistema se realizaba a través de la Disposición adicional octava de la Ley 30/1984, de 2 de agosto $^{2}$, de tal manera que en nada se alteraba la concepción de este apartado de ordenación de la función pública.

La titulación oficial académica, pues, es el aglutinante entre la diversidad de cuerpos/escalas y categorías existentes, y el auténtico sostén del desempeño de la función pública a través del sistema de puestos de

1 Así los establecía el artículo 3. : :La proporcionalidad correspondiente a los niveles de titulación exigibles para el ingreso en los Cuerpos, Escalas o Plazas de, la Administración Civil del Estado, a que se refiere el punto uno del artículo anterior, será la siguiente:

\begin{tabular}{llc}
\hline & \multicolumn{1}{c}{ Nivel de titulación } & Proporcionalidad \\
\hline Educación Universitaria (Doctores, Licenciados, Arquitectos, Ingenieros y equivalentes) & 10 & \\
\hline $\begin{array}{l}\text { Educación Universitaria (Diplomados, Arquitectos Técnicos, Ingenieros Técnicos, Titulados de Formación } \\
\text { Profesional de tercer grado y equivalentes) }\end{array}$ & 8 \\
\hline Enseñanzas Medias (Bachillerato, Titulados de Formación Profesional de segundo grado y equivalentes) & 4 \\
\hline Educación General Básica (Graduado Escolar y equivalentes) & 3 \\
\hline Educación General Básica (certificado de Escolaridad)
\end{tabular}

2 «Los Cuerpos y Escalas declarados a extinguir que actualmente tengan asignados los índices de proporcionalidad 10, 8, 6, 4 y 3, pasarán a integrarse respectivamente, a partir de la vigencia de esta Ley, en los grupos $A, B, C, D$ y $E$ establecidos en el artículo 25». 
REALA. Nueva Época - N. 10, Octubre 2018 - ISSN: 1989-8975 - DOI: 10.24965/reala.v0i10.10514 - [Págs. 96-108]

Sobre la aplicabilidad del grupo B del artículo 76 del Texto Refundido del Estatuto Básico del Empleado Público como grupo de ...

Agustín Juan Gil Franco

trabajo. Todo ello, sin perjuicio, de constituir un poderoso sistema común y básico a toda la función pública del Estado, tanto desde el punto de vista retributivo como en el de la propia carrera administrativa. De hecho, hoy en día la determinación de la retribución asignable a dichos grupos de clasificación de los distintos cuerpos/escalas y categorías constituye un elemento clave en la política económica general del país ${ }^{3}$.

El antedicho traslado entre titulación y grupo de clasificación, operado por la ley en 1984, no ofreció dificultad alguna por cuanto que los grados académicos se correspondían con los grupos de clasificación. El sistema también demostró que el acceso a los cuerpos y escalas, salvo aquellos denominados como especiales $^{4}$, no requerían un sistema formativo propio, específico y peculiar para los servidores públicos de entre los generalmente ofertados tras la conclusión de los ciclos formativos elementales y obligatorios dentro de nuestro sistema educativo. De igual forma, la clasificación por grupos desplazaba la centralidad del «cuerpo» funcionarial en cuanto único sistema de progresión en la carrera, por el desempeño del puesto, consagrando con ello el sistema mixto introducido por la Ley de 1964.

El artículo 76 del Estatuto Básico del Empleado Público ${ }^{5}$, partiendo de la ya existente, venía a establecer una nueva clasificación para los distintos cuerpos, Escalas y Categorías, prosiguiendo aparentemente sobre la senda marcada por el artículo 25 de la Ley 30/1984, de 2 de agosto, de medidas para la reforma de la Función Pública. El sistema se sustenta nuevamente sobre la titulación académica oficial y sus diferentes grados, de tal manera que la obtención de la general otorgada sobre la superación de un grado académico oficial fuera el núcleo sobre el que agrupar los cuerpos y escalas, todo ello, sin perjuicio de las especificidades requeridas para los puestos de trabajo y funciones propias otorgadas a los mismos.

Pero el anterior sistema de grupos, da paso a la desagregación de éstos, en los nuevos subgrupos, y la creación, no obstante lo anterior, de un nuevo grupo con la idea asimismo de dar cabida a una nueva titulación académica oficial, resultado de completar los estudios y prácticas en Formación profesional. Esta novedad se sustancia en la creación de un nuevo Grupo B cuya titulación de encuadre para el acceso general a los cuerpos o escalas en que sean clasificadas en dicho grupo es «estar en posesión del título de Técnico Superion». Finalmente, la Disposición adicional sexta, del TREBEP crea las denominadas agrupaciones profesionales sin requisito de titulación, (las supuestas herederas del anterior grupo «E»), que dejaría abierta la clasificación operada por el artículo 76 TREBEP, ya que, además de los Grupos clasificatorios establecidos en el artículo 76 del TREBEP, las Administraciones Públicas pueden establecer otras agrupaciones diferentes de las enunciadas, para cuyo acceso no se exija estar en posesión de alguna de las titulaciones previstas en el sistema educativo ${ }^{6}$.

La notable imprecisión en cuanto a la correspondencia entre titulación y grupo/subgrupo operada en el EBEP de 2007, dada la reciente implantación del nuevo sistema de titulación académica universitaria fruto del Espacio Europeo de Educación superior ${ }^{7}$, hubiera podido ser corregido en el Texto refundido de 2015,

${ }_{3}^{3}$ De hecho, por ejemplo, el artículo 18.11 de la Ley 3/2017, de 27 de junio, de Presupuestos Generales del Estado para el año 2017, es claro al respecto: "Este artículo tiene carácter básico y se dicta al amparo de los artículos 149.1.13. ${ }^{a}$ y 156.1 de la Constitución».

${ }^{4}$ El del aún vigente artículo 24.1 del Decreto 315/1964, de 7 de febrero, por el que se aprueba la Ley articulada de Funcionarios Civiles del Estado, nos ofrece una definición "Son funcionarios de Cuerpos especiales los que ejercen actividades que constituyen el objeto de una peculiar carrera o profesión y los que tienen asignado dicho carácter por razón de las circunstancias concurrentes en la función administrativa que les está encomendada». Algo que en el ámbito de la función pública local se recoge en el artículo 170 del Real Decreto Legislativo 781/1986, de 18 de abril, por el que se aprueba el Texto Refundido de las disposiciones legales vigentes en materia de Régimen Local: «Tendrán la consideración de funcionarios de Administración Especial los que tengan atribuido el desempeño de las funciones que constituyen el objeto peculiar de una carrera, profesión, arte u oficio».

${ }^{5}$ Esta es la clasificación que realiza: «Grupo A: Dividido en dos Subgrupos, A1 y A2.

Para el acceso a los cuerpos o escalas de este Grupo se exigirá estar en posesión del título universitario de Grado. En aquellos supuestos en los que la ley exija otro título universitario será éste el que se tenga en cuenta.

La clasificación de los cuerpos y escalas en cada Subgrupo estará en función del nivel de responsabilidad de las funciones a desempeñar y de las características de las pruebas de acceso.

Grupo B. Para el acceso a los cuerpos o escalas del Grupo B se exigirá estar en posesión del título de Técnico Superior.

Grupo C. Dividido en dos Subgrupos, C1 y C2, según la titulación exigida para el ingreso.

C1: Título de Bachiller o Técnico.

C2: Título de Graduado en Educación Secundaria Obligatoria».

${ }^{6}$ A modo de ejemplo, el artículo 43 de la Ley 2/2015, de 29 de abril, del empleo público de Galicia, crea la agrupación profesional del personal funcionario subalterno de la Administración general de la Comunidad Autónoma de Galicia. Se integra en esta agrupación profesional el personal funcionario seleccionado sin la exigencia de estar en posesión de alguna de las titulaciones previstas en el sistema educativo para ocupar puestos que tengan atribuidas funciones ordinarias de vigilancia, custodia, reparto de correspondencia y documentación, transporte manual, central telefónica, reprografía y otras semejantes.

7 Se regulan por el Real Decreto 1393/2007, de 29 de octubre, por el que se establece la ordenación de las enseñanzas universitarias oficiales, modificado por el Real Decreto 99/2011, de 28 de enero, por el que se regulan las enseñanzas oficiales de doctorado y el Real Decreto 43/2015, de 2 de febrero. 
ya que el Máster universitario entra a formar parte como grado académico oficial dentro de la Educación superior junto al título de graduado universitario y doctor. Si se hubiera pretendido continuar con la clasificación grupo/titulación quizás hubiera sido interesante que los dos subgrupos del grupo A se hubieran hecho converger con una y otra titulación: el A1 con la necesidad de poseer el título de Master Universitario oficial o equivalente/doctor, etc. y el A2 con la de poseer el título de graduado universitario o equivalente ${ }^{8}$.

Sin embargo, la clasificación implanta una novedad sustancial, y es que se establece el mismo requisito de titulación académica oficial de acceso para los cuerpos/escalas tanto para el subgrupo A1 como para el subgrupo A2, para los que se exige título universitario de Grado. Esta identidad se explica porque «la clasificación de los cuerpos y escalas en cada Subgrupo estará en función del nivel de responsabilidad de las funciones a desempeñar y de las características de las pruebas de acceso». Lo cual supone introducir un factor adicional, -podríamos decir «ex post»-, que va más allá de la titulación académica y es el tramo de desempeño de puestos asignados a cada subgrupo, de tal manera que estos tramos -la escala de niveles de puestos de trabajo del artículo 71 de Real Decreto 364/1995, de 10 de marzo ${ }^{9}$ - son ahora mucho más decisivos ya que podría darse -si se optase por este sistema de carrera administrativa- una asignación de tramos de niveles a Cuerpos/escalas y categorías determinados. El sistema de clasificación, por tanto, se transmuta en el caso de los subgrupos A1 y A2, dejando como elemento clave de diferenciación, en este caso, el desempeño del puesto en las Relaciones de puestos de trabajo; y las denominadas Agrupaciones profesionales que quedan abiertas a lo que dispongan las leyes de función pública tanto de la AGE como de las Comunidades Autónomas. Con esto y dado el año en que se llevó a cabo la aprobación del Texto Refundido del EBEP, quizás pierda su razón de ser la disposición transitoria $3{ }^{a}$, ya que la implantación de los nuevos títulos universitarios auspiciada en 2007, ya era -y los es en estos momentos- una realidad más que consolidada.

Curiosamente los apartados 35 y 36 relativos a los grupos profesionales dedicados por la Comisión de Expertos para el estudio y preparación del Estatuto Básico del Empleado Público, tratan de forma más detenida sobre la implicación de la implantación de las nuevas titulaciones universitarias exponentes de la creación de un espacio europeo de educación superior (Declaración de Bolonia) en los grupos de clasificación de los cuerpos/escalas y categorías de funcionarios, pero no se hace alusión alguna sobre la posibilidad de creación de grupos/subgrupos ligados a las titulaciones académicas de los ciclos formativos de la formación profesional ${ }^{10}$.

\section{EL NUEVO GRUPO B DE CLASIFICACIÓN DE CUERPOS, ESCALAS Y CATEGORÍAS EN LA LEGISLACIÓN DEL ESTATUTO DE LOS FUNCIONARIOS}

El, tantas veces citado, artículo 76 del EBEP -también recogido por el TREBEP-creaba un nuevo grupo de clasificación, el grupo B, con la idea de dar cabida a otra titulación académica oficial, dentro de nuestro sistema educativo, la titulación de Técnico superior. Con todo, el mandato legislativo del artículo 76 EBEP (TREBEP) debía complementarse necesariamente con las medidas transitorias que el mismo texto

\footnotetext{
8 Esta medida quizás hubiera chocado frontalmente con las titulaciones específicas exigibles en determinados cuerpos/escalas y categorías de la Administración pero también existen medidas alternativas a través de cada ley de función pública autonómica y de la Administración General del Estado para solventar estos posibles problemas.

9 «Los intervalos de los niveles de puestos de trabajo que corresponden a cada Cuerpo o Escala, de acuerdo con el Grupo en el que figuren clasificados, son los siguientes:
}

\begin{tabular}{lcc}
\hline Cuerpos o Escalas & Nivel mínimo & Nivel máximo \\
\hline Grupo A & 20 & 30 \\
\hline Grupo B & 16 & 26 \\
\hline Grupo C & 11 & 22 \\
\hline Grupo D & 9 & 18 \\
\hline Grupo E & 7 & 14 \\
\hline
\end{tabular}

2. En ningún caso los funcionarios podrán obtener puestos de trabajo no incluidos en los niveles del intervalo correspondiente al Grupo en el que figure clasificado su Cuerpo o Escala».

10 Véase dichos apartados en el Informe Comisión de Expertos para el estudio y preparación del Estatuto Básico del Empleado Público, págs. 85 a 88. 
REALA. Nueva Época - N.o 10, Octubre 2018 - ISSN: 1989-8975 - DOI: 10.24965/reala.v0i10.10514 - [Págs. 96-108]

Sobre la aplicabilidad del grupo B del artículo 76 del Texto Refundido del Estatuto Básico del Empleado Público como grupo de ...

Agustín Juan Gil Franco

legal determinara dado que operaba una transformación en la clasificación del conjunto de cuerpos/escalas y categorías de funcionarios existentes a la entrada en vigor de la ley. Esa misión se atribuye a la Disposición transitoria tercera ${ }^{11}$ que en relación con el nuevo grupo $B$ tan sólo señala que los funcionarios del Subgrupo C1 que reúnan la titulación exigida podrán promocionar al Grupo A sin necesidad de pasar por el nuevo Grupo $\mathrm{B}$, de acuerdo con los requisitos establecidos por el mismo estatuto en relación con la promoción interna.

No es sino con la Resolución de 21 de junio de 2007, de la Secretaría General para la Administración Pública, por la que se publican las Instrucciones de 5 de junio de 2007, para la aplicación del Estatuto Básico del Empleado Público en el ámbito de la Administración General del Estado y sus organismos públicos, para encontrar alguna medida que pueda tener como referencia el nuevo grupo B, y así se establece que «la integración de los Cuerpos y Escalas en los nuevos grupos y subgrupos de clasificación es automática». Lo cual implica que no es procedente cualquier tipo de trasposición legislativa o normativa sobre esta cuestión, dada la condición de ley básica del EBEP, y, desde luego, que su vigencia y aplicación es automática «per se». Ahora bien, la clasificación «automática o en bloque» establecida tanto para los subgrupos A1 y A2, como para los $\mathrm{C} 1, \mathrm{C} 2$ y agrupaciones profesionales, no se prevé para el grupo B, para el que la Resolución de 21 de julio de 2007, establece que "esta integración automática no resulta aplicable al nuevo grupo B que queda reservado a quienes estén en posesión del título de Técnico Superior, por no existir en los actuales grupos de clasificación uno equivalente». Más bien parece apuntar a un «integración» individualizada, «no escalafonada» prevista para aquellos funcionarios que poseyeran la titulación de Técnico Superior.

La cuestión a determinar, pues, es si el nuevo grupo B despliega todos sus efectos sobre los distintos ámbitos de función pública y es de aplicación real y sustantiva sobre los mismos. Entendemos que hay poderosas razones para señalar la plena aplicabilidad del nuevo grupo B en la clasificación de cuerpos, escalas y categorías. El primer argumento es que si la disposición transitoria tercera opera una transformación/ adaptación de los grupos de clasificación anteriores con especial mención a las titulaciones universitarias no adaptadas a los nuevos sistemas de clasificación en cuanto a su requisito de acceso a los nuevos grupos/ subgrupos, y no hace alusión alguna a la titulación del grupo B, «Técnico superior» ${ }^{12}$, que es considerada como única titulación clave para el acceso al mismo, dado que la formación profesional de tercer grado mencionada por la Ley 30/1984, de 2 de agosto, como equiparable a los efectos de clasificación en el antiguo grupo B, no tuvo implantación en realidad ${ }^{13}$; es evidente que la aplicación no pasa por otra norma más que la creación directa de los cuerpos, escalas y categorías que contengan dicha titulación como requisito para su ingreso.

La titulación «Técnico superior» en formación profesional está implantada plenamente desde que así la creara el artículo 44 de la Ley Orgánica 2/2006 de 3 de mayo, de Educación, e incluso ha servido de base, para regular profesiones en sectores específicos de actividad. Este es el caso, por tan solo destacar un sector concreto profesional ${ }^{14}$, de lo establecido por los artículos 13 , 14 y 15 de la reciente Ley 6/2016, de 24 de noviembre, por la que se ordena el ejercicio de las profesiones del deporte en la Comunidad de Madrid, y en los que se determinan los requisitos para el ejercicio de las profesiones reguladas del deporte, para la que se establece explícitamente la titulación de Técnico Superior en Animación de Actividades Físicas y Deportivas como habilitante para el desarrollo de determinadas profesiones. O lo establecido por los artículos 20 y 21 del Real Decreto 1363/2007, de 24 de octubre, por el que se establece la ordenación general de las enseñanzas deportivas de régimen especial, y en los que explícitamente se mencionan «los títulos de Técnico deportivo y de Técnico deportivo superior» los cuales se completan «con la de la modalidad deportiva de que se trate y, en su caso, la especialidad que corresponda» quedando ambos títulos dentro del

11 «Transitoriamente, los Grupos de clasificación existentes a la entrada en vigor de la Ley 7/2007, de 12 de abril, se integrarán en los Grupos de clasificación profesional de funcionarios previstos en el artículo 76, de acuerdo con las siguientes equivalencias:

Grupo A: Subgrupo A1. Grupo B: Subgrupo A2. Grupo C: Subgrupo C1. Grupo D: Subgrupo C2. Grupo E: Agrupaciones Profesionales a que hace referencia la disposición adicional sexta».

12 El Título de Técnico superior se establece en el artículo 44 de la Ley Orgánica 2/2006, de 3 de mayo, de Educación, y explicitado en el artículo 32 del Real Decreto 1147/2011, de 29 de julio, por el que se establece la ordenación general de la formación profesional del sistema educativo.

13 Tampoco tiene su equivalente, por ejemplo, el Título de Maestro Industrial se declara equivalente a todos los efectos al título genérico de Técnico Especialista, según lo previsto en la Orden Ministerial de 21 de noviembre de 1975 (BOE del 25).

14 Otros sectores profesionales regulados son por ejemplo el Real Decreto 779/2013, de 11 de octubre, por el que se establece el título de Técnico Superior en Promoción de Igualdad de Género y se fijan sus enseñanzas mínimas, el Real Decreto 1074/2012, de 13 de julio, por el que se establece el título de Técnico Superior en Integración Social y se fijan sus enseñanzas mínimas, y el Real Decreto 384/2011, de 18 de marzo, por el que se establece el título de Técnico Superior en Educación y Control Ambiental y se fijan sus enseñanzas mínimas. 
REALA. Nueva Época - N.o 10, Octubre 2018 - ISSN: 1989-8975 - DOI: 10.24965/reala.v0i10.10514 - [Págs. 96-108]

Sobre la aplicabilidad del grupo B del artículo 76 del Texto Refundido del Estatuto Básico del Empleado Público como grupo de ...

Agustín Juan Gil Franco

denominado «Catálogo de las Enseñanzas Deportivas» ${ }^{15}$. Por tanto, no podemos aducir la inexistencia real de la titulación como elemento determinante para la aplicabilidad real del nuevo grupo B en el sistema de clasificación profesional.

\section{POTESTAD DE LAS ADMINISTRACIONES LOCALES PARA LA CREACIÓN DE CATEGORÍAS PROPIAS DE FUNCIONARIOS DENTRO DEL SISTEMA DE FUNCIÓN PÚBLICA LOCAL}

La Ley 7/1985, de 2 de abril, reguladora de las Bases del Régimen Local, (en adelante LRBRL) no ofrece una regulación, siquiera sumaria sobre esta cuestión, a pesar de la crucial importancia que este aspecto tiene para el régimen de función pública local ${ }^{16}$. De ahí que haya de acudirse al sistema de fuentes pertrechado por el artículo 92 de la LRBRL ${ }^{17} y$, por remisión de éste, al establecido por el artículo 3 del TREBEP ${ }^{18}$, en el que se establece un doble régimen de sistema de fuentes respecto de los funcionarios locales, reflejo de la peculiaridad de unos cuerpos/categorías respecto de otros.

Por tanto, respecto del régimen de ordenación y de clasificación de los funcionarios locales propios se ha de tener en cuenta la legislación estatal «que le resulte de aplicación», en el que, naturalmente, habrá de incluirse la legislación básica estatal local restante a la LRBRL, o derivada de esta misma, la legislación estatal sobre esta cuestión, además naturalmente del propio Estatuto Básico del Empleado Público, la legislación de las comunidades autónomas relativas, en primer término, al régimen local en desarrollo de la LRBRL y las disposiciones que al respecto de la ordenación de cuerpos/escalas y categorías de funcionarios en el ámbito local pudieran haberse establecido en las respectivas leyes de función pública autonómicas. Ahora bien, no puede olvidarse el inciso final del precepto, el cual implica no sólo una cláusula de garantía en cuanto al modelo de función pública propio que pudieran establecer las distintas corporaciones locales, sino también una cláusula de habilitación normativa dentro de la regulación legislativa sobre esta cuestión.

Dentro de la regulación estatal local, el texto legislativo que con mayor detalle trata de la cuestión de la clasificación y creación de cuerpos/escalas y categorías, es el Real Decreto Legislativo 781/1986, de 18 de abril, por el que se aprueba el Texto Refundido de las disposiciones legales vigentes en materia de Régimen Local, (en adelante TRRL), en concreto el artículo 131, el cual dispone que «los funcionarios de carrera que no ocupen puestos de trabajo reservados a funcionarios con habilitación de carácter nacional se integrarán en las escalas, subescalas, clases y categorías de cada Corporación, con arreglo a lo que se previene en la presente Ley. Las subescalas, clases y categorías quedarán agrupadas conforme a la legislación básica del Estado en los grupos que ésta determine, de acuerdo con la titulación exigida para su ingreso». Precepto que se ve completado por el artículo 167.2 TRRL (el párrafo primero es un repetición del artículo 131), y en el que se apunta el sistema de ordenación y estructura de los funcionarios locales propios, que quedarían encuadrados dentro de dos grandes Escalas, concibiéndose las mismas como dos sectores de actividad administrativa independientes, y con una sustantividad propia tal, como para ser objeto de creación y adscripción de subescalas y categorías de funcionarios específicas. El tenor literal del precepto es claro en cuanto al necesario agrupamiento de los distintos funcionarios en una u otra estructura de función pública -la General o la Especial- ya que se dice «que se integrarán». De esta manera, no caben otros sectores de función pública para los funcionarios locales propios dentro de cada Corporación local.

Ciertamente, podemos hablar de un sistema de ordenación propia de las subescalas y categorías de funcionarios locales propios, directamente vinculado a las potestades de organización otorgadas «ex lege»

15 A este respeto, y en su cumplimiento, tenemos el caso concreto y reciente de la Orden ECD/482/2017, de 24 de mayo, por la que se establece el currículo del ciclo de grado superior correspondiente al Título de Técnico Deportivo Superior en Baloncesto (BOE 29 de mayo de 2017).

16 Sobre la cuestión de qué ámbito legislativo básico debe regular el estatuto del personal funcionario propio de las Administraciones locales, si el legislador básico del régimen local o el legislador básico de la función pública, véase FUENTETAJA, J. A. (2007): "El Estatuto Básico del Empleado Público", en Revista de Administración Pública, núm. 174 y FUENTETAJA, J. A. (2010): "Función pública local”, en FUENTETAJA PASTOR, J. A. y FERNÁNDEZ RODRÍGUEZ, C., Manual de Derecho local. Madrid. Iustel. (1. a edición).

17 "Los funcionarios al servicio de la Administración local se rigen, en lo no dispuesto en esta Ley, por la Ley 7/2007, de 12 de abril, del Estatuto Básico del Empleado Público, por la restante legislación del Estado en materia de función pública, así como por la legislación de las Comunidades Autónomas, en los términos del artículo 149.1.18. ${ }^{a}$ de la Constitución».

18 «1. El personal funcionario de las entidades locales se rige por la legislación estatal que resulte de aplicación, de la que forma parte este Estatuto y por la legislación de las comunidades autónomas, con respeto a la autonomía local. 2. Los Cuerpos de Policía Local se rigen también por este Estatuto y por la legislación de las comunidades autónomas, excepto en lo establecido para ellos en la Ley Orgánica 2/1986, de 13 de marzo, de Fuerzas y Cuerpos de Seguridad.». 
REALA. Nueva Época - N. 10 , Octubre 2018 - ISSN: 1989-8975 - DOI: 10.24965/reala.v0i10.10514 - [Págs. 96-108]

Sobre la aplicabilidad del grupo B del artículo 76 del Texto Refundido del Estatuto Básico del Empleado Público como grupo de ...

Agustín Juan Gil Franco

[artículo 4.1 a) de la LRBRL] e inserto, por ello, dentro del ámbito de la autonomía local que el TREBEP llama a preservar por la propia legislación de función pública de las instancias territoriales superiores, el Estado y las CC.AA. (artículo 3.1 del TREBEP). Este es el sentido que quiere dar a esta regulación de función pública, la temprana sentencia del Tribunal Constitucional, la STC 54/1982 ${ }^{19}$, en la que se afirma «en este sentido, es de señalar que de la legislación relativa a los funcionarios de las Corporaciones locales puede deducirse un principio de ordenación de los funcionarios no pertenecientes a Cuerpos Nacionales, en Grupos (de Administración General y de Administración Especial) dentro de cada Corporación y la subdivisión de aquellos grupos en los subgrupos que cita y éstos, en su caso, en clases y categorías (texto articulado parcial de la Ley 41/1975, aprobado por Real Decreto 3046/1977, de 6 de octubre, especialmente los arts. 30, 68 y 87)». Debe puntualizarse que el tenor literal de las disposiciones mencionadas por esta sentencia ha permanecido inalterado y ha sido incorporado en el TRRL, por lo que es de importancia grande lo que continúa diciendo la precitada sentencia: «de la consideración de esta legislación, y de la que regula el régimen de los funcionarios públicos del Estado se deduce que la ordenación de los funcionarios en Cuerpos no es un principio organizativo que se imponga con carácter excluyente a todas las Administraciones públicas, pues junto a la existencia de Cuerpos está también el criterio vigente en el régimen de las Corporaciones locales de organizar a sus funcionarios no pertenecientes a Cuerpos Nacionales en grupos, subgrupos, clases y categorías».

De ahí que podamos afirmar, sin lugar a duda alguna, que las potestades de ordenación de las categorías de funcionarios locales propios, -entre las que podemos incluir la clasificación, y siempre dentro de los contornos básicos de la cuestión-, es una facultad propiamente local, ínsita en su autonomía. A este respecto, conviene hacer mención aquí lo afirmado por el artículo 72 del TREBEP, para el que esta potestad es propia e inherente de una Administración pública territorial: «En el marco de sus competencias de auto organización, las Administraciones Públicas ${ }^{20}$ estructuran sus recursos humanos de acuerdo con las normas que regulan la selección, la promoción profesional, la movilidad y la distribución de funciones y conforme a lo previsto en este capítulo».

El artículo 167 del TRRL ofrecía una clasificación de las subescalas y categorías profesionales funcionariales desde propiamente la titulación académica, bien es verdad que no desde esta perspectiva directamente, sino deduciéndose de la misma: "la escala de administración general se divide en las subescalas siguientes: a) Técnica; b) de Gestión; c) Administrativa; d) Auxiliar; e) Subalterna». Es evidente que la estructura recoge la anterior clasificación de grupos de acuerdo con la titulación exigida para su ingreso. El detalle con que se lleva a cabo esta clasificación se torna, en cambio, más etéreo en relación con al ámbito de la denominada Escala de administración especial para la que tan sólo vienen a delimitarse dos subescalas, en el apartado $3 .^{\circ}$ de dicho artículo: «la Escala de Administración Especial se divide en las Subescalas siguientes: a) Técnica; b) de Servicios Especiales». Este proceder viene a justificarse por la propia ley al señalar, en su artículo 172.1 TRRL, que «pertenecerán a la Subescala de Servicios Especiales los funcionarios que desarrollen tareas que requieran una aptitud específica, y para cuyo ejercicio no se exija, con carácter general, la posesión de títulos académicos o profesionales determinados».

Pero de todos es conocido cómo determinadas titulaciones técnicas, en su día, catalogadas dentro del sistema de grados académicos como "Arquitectura Técnica» o «Ingenierías Técnicas» O «Diplomaturas universitarias» necesitaban de su posesión para habilitar actuaciones profesionales determinadas dentro de este ámbito de actuación administrativa local, de tal manera que, agrupadas en torno a la Subescala técnica de administración especial o la subescala de servicios especiales, las distintas corporaciones locales crearon categorías profesionales de funcionarios sin aparente habilitación legislativa específica. En efecto, podemos afirmar que el anterior grupo B (hoy en día subgrupo A2), conforme a la clasificación establecida por el artículo 25 de la Ley 30/1984, de 2 de agosto, se implantó en las Corporaciones locales, incluso antes que la redacción dada al apartado $2{ }^{\circ}$ del artículo 167 del TRRL por el número uno del artículo 60 de la Ley 53/2002, de 30 de diciembre, de Medidas Fiscales, Administrativas y del Orden Social, por la que teóricamente se introducía la clasificación del grupo B del mencionado artículo 25 de la Ley 30/1984, de 2 de agosto, en el ámbito de la función pública local. Todo lo cual no hacía sino «constatar» un práctica administrativa clara en dicho sentido y que en el caso, por ejemplo del Ayuntamiento de Madrid, en el Pleno de 29 de octubre de 1993, acordaba la reordenación y clasificación de las distintas categorías de funcionarios pertenecientes al

19 STC 54/1982, del 26 de julio, Pleno, Conflicto constitucional positivo de competencia núm. 25/1982.

20 Esta potestad propia de organización se ve delimitada siempre en el sentido de que son funcionarios los que han de actuar en las actividades profesionales en «el ejercicio de las funciones que impliquen la participación directa o indirecta en el ejercicio de las potestades públicas o en la salvaguardia de los intereses generales» (artículo 92.3 LRBRL). 
REALA. Nueva Época - N.o 10, Octubre 2018 - ISSN: 1989-8975 - DOI: 10.24965/reala.v0i10.10514 - [Págs. 96-108]

Sobre la aplicabilidad del grupo B del artículo 76 del Texto Refundido del Estatuto Básico del Empleado Público como grupo de ...

Agustín Juan Gil Franco

grupo B (del art. 25 de la Ley 30/1984), «sic», cuando supuestamente la habilitación legal no se produjo hasta 2002. Es decir, que el anterior grupo B (hoy subgrupo A2) existía y «clasificaba» categorías funcionariales en los Ayuntamientos con anterioridad a la habilitación legal. Abundando más en lo señalado, no podemos dudar de las facultades locales dado que, si realizamos una lectura rápida del artículo 167.4 del TRRL, se faculta por el mismo a cada una de las Corporaciones locales para la creación de escalas, subescalas, clases de funcionarios y la clasificación de los mismos dentro de cada una de ellas, de acuerdo con lo previsto en dicha Ley. Aún hay más, y es que sobre esta cuestión, dado el ejemplo antes apuntado, la Comunidad de Madrid no se ha separado de las disposiciones del TRRL: de hecho, el artículo 107 de Ley 2/2003, de 11 de marzo, de Administración Local de la Comunidad de Madrid, reproduce el mismo tenor literal que el antedicho artículo 167 del TRRL. De ahí que no podemos hablar de novedad legislativa que imponga requisitos o condiciones nuevas a la creación y ordenación de categorías funcionariales para las Administraciones locales del ámbito de la Comunidad de Madrid, para las que se predica, en efecto, una autonomía amplia.

Esto, sin duda, tiene el significado de otorgar una habilitación directa desde la norma básica estatal, hasta la potestad normativa local que puede delimitar y crear categorías conforme al encuadramiento que hubiera determinado esta misma legislación básica de funcionarios. Es cierto que el artículo 75.2 del TREBEP establece que los cuerpos y escalas de funcionarios se crean, modifican y suprimen por ley de las Cortes Generales o de las Asambleas legislativas de las comunidades autónomas pero la habilitación legal contenida tanto en el artículo 167.4 TRRL, como la del artículo 107 de Ley 2/2003, de 11 de marzo, de Administración Local de la Comunidad de Madrid, por continuar con el mismo ejemplo, es lo suficientemente precisa y derivativa de una voluntad clara del legislador de reconocer facultades, en este aspecto tan claramente organizativo, de desarrollo normativo por estar íntimamente ligadas a la autonomía local. Así pues, el acto de creación por parte de una Corporación de una nueva categoría funcionarial y su adscripción a un grupo/subgrupo determinado de la clasificación, no es un acto "contra legem» o, mejor de un acto «ultra vires», sino una acto pleno de ejercicio de la autonomía local. De hecho, esta operación legislativa se reproduce igualmente dentro del contexto de la autonomía universitaria, reconocida por nuestro texto constitucional en el artículo 27.10. De esta manera y en consonancia directa con lo que estamos exponiendo, el artículo 75.1 de la Ley Orgánica 6/2001, de 21 de diciembre, de Universidades, otorga directamente dicha facultad a las Universidades que podrán crear escalas de personal funcionario propio de acuerdo con los grupos de titulación exigidos de conformidad con la legislación general de la función pública. El paralelismo es indudable entre una y otra Administración pública.

La cuestión fundamental es determinar la suficiencia en las predeterminaciones legislativas mencionadas, con fundamento en las previstas por nuestro Tribunal Constitucional respecto de la creación, refundición y supresión de cuerpos y escalas de funcionarios (STC 99/198721), como para que pueda procederse a la creación de categorías funcionariales desde una acción normativa de un poder ajeno al legislativo aunque lógicamente situado dentro de sus márgenes.

\section{EL GRUPO B COMO GRUPO DE CLASIFICACIÓN DE LOS FUNCIONARIOS PROPIOS DE LAS ADMINISTRACIONES LOCALES}

Dicho esto, ¿podemos considerar suficientemente delimitado por la legislación básica de aplicación, el grupo B, creado por el artículo 76 del EBEP al que deberían adscribirse cualquiera de los cuerpos y escalas para los que se exija estar en posesión del título de Técnico Superior? ¿Podría, pues, una Corporación local crear categorías de funcionarios con el requisito de titulación mencionado, en sus diversas especializaciones, con adscripción directa al grupo B mencionado?

A la primera cuestión ya hemos hecho alusión en el punto anterior. Y respecto de la segunda, entendemos que tanto el TREBEP como las diferentes Leyes de Presupuestos Generales del Estado ofrecen, sin duda alguna, respecto a esta cuestión, elementos suficientes para entender aplicable dicho grupo de forma real. Y ello, no sólo sobre carácter básico de las leyes apuntadas sino sobre la propia razón de la medida legislativa que no se plantea sobre una «no-aplicación» o postergación «sine die» -las disposiciones transitorias nada dicen al respecto- sino sobre el despliegue de efectos sobre cada ámbito competencial del sistema de clasificación de cuerpos y escalas en el sistema español de función pública. Parece como si el

21 STC 99/1987, de 11 de junio, recurso de inconstitucionalidad núm. 763/84. FJ 3. ${ }^{\circ}$. 
REALA. Nueva Época - N.o 10, Octubre 2018 - ISSN: 1989-8975 - DOI: 10.24965/reala.v0i10.10514 - [Págs. 96-108]

Sobre la aplicabilidad del grupo B del artículo 76 del Texto Refundido del Estatuto Básico del Empleado Público como grupo de ...

Agustín Juan Gil Franco

legislador básico se limitara a señalar la posibilidad y los elementos necesarios para su desarrollo en una fase legislativa o reglamentaria posterior (ordenanzas/reglamentos locales), siempre en atención a las características propias y genuinas de cada modelo de función pública que se diseñe. En este sentido, la STC $172 / 1996{ }^{22}$, afirma que "el sentido y alcance de aquéllas ha de ser obtenido mediante los criterios o técnicas hermenéuticas propias de la lógica jurídica, atendiendo por supuesto a su función y a su finalidad, sin quedarse en la superficie literal del texto. Por otra parte, el desarrollo implica de suyo no sólo un complemento más detallado de lo que sea genérico sino también de lo específico, teniendo en cuenta las peculiaridades de cada sector o de cada Administración».

El carácter basal de una norma o disposición legislativa, desde el sustento constitucional del artículo 149.1.18 CE, no impide, desde luego, su aplicabilidad directa ya que no necesita intermediación legislativa alguna para su pleno despliegue de efectos. Tanto las Leyes de Presupuestos que repetidamente aluden al grupo B como el propio TREBEP, contienen «ámbitos verdaderamente nucleares del "régimen estatutario de los funcionarios públicos"» tal y como señala la STC $1 / 2003^{23}$, y se cumple con ello lo que, de forma repetida, ha señalado nuestro Tribunal Constitucional como misión de la norma básica, por todas la STC 182/198824: "es necesario garantizar "una definición clara y precisa de los marcos básicos delimitadores de las competencias autonómicas que, siendo fácilmente reconocibles, evite la incertidumbre jurídica que supone para las Comunidades Autónomas asumir, sin dato orientativo alguno, la responsabilidad de investigar e indagar, en la masa ingente de disposiciones legislativas y reglamentarias estatales, una definición que es al Estado a quien corresponde realizar por encargo directo de la Constitución" (fundamento jurídico 6. ${ }^{\text {))». }}$

En efecto, como también afirma la STC 172/1996 ${ }^{25}$, esta misión consistiría en la plasmación del "común denominador normativo para todos en un sector determinado, pero sin olvidar, en su dimensión intelectual, el carácter nuclear, inherente al concepto. Incorpora, pues, la acepción de fundamento o apoyo principal de algo, con vocación por la esencia, no de lo fenoménico o circunstancial (STC 102/1995)». De ahí que podamos concluir que la función de esta legislación clasificatoria estatal es, como afirma la STC 197/199626, para la legislación básica, "la garantía de certidumbre jurídica» respecto de la cuestión que ahora tratamos: la plena aplicabilidad del grupo B como sistema de clasificación de cuerpos, escalas, subescalas y categorías del personal funcionario.

Por consiguiente, la legislación básica relativa al grupo B del artículo 76 TREBEP, tiene elementos suficientes de «certidumbre jurídica» como para poder ser aplicables en las Administraciones locales no sólo porque la legislación básica es aplicable «per se», como ya hemos destacado, sino porque además la legislación autonómica ha remitido cualquier actuación en cuanto a la ordenación de la clasificación de escalas, subescalas y categorías a las mismas corporaciones locales. Es más, en la ciudad de Madrid, por ejemplo, en virtud del artículo 11.1 p) de la Ley 22/2006, de 4 de julio, de Capitalidad y de Régimen Especial de Madrid, corresponde propiamente al Pleno no solo la creación de escalas, subescalas y clases de funcionarios, sino también la atribución a los mismos, de la condición de agente de la autoridad, en atención a las funciones que les correspondan ejercer. Esta disposición viene a particularizar y reafirmar lo expuesto por parte de las competencias que el artículo 167.4 del TRRL y del artículo 107 de la Ley 2/2003, de 11 de marzo, de Administración Local de la Comunidad de Madrid, otorgan a las Corporaciones locales. Artículos, por cierto, de idéntico tenor literal y sin duda alguna en cuanto a las facultades locales en esta materia.

No hay, pues, disposición legislativa alguna que impida la plena aplicabilidad a las Administraciones locales, de dicho grupo de clasificación profesional, si éstas optaran por la creación de categorías de funcionarios para cuyo acceso se establezca la titulación de Técnico Superior, de forma genérica, o sobre cualquiera de las especialidades de las enseñanzas regladas de la formación profesional que es a la que la ley básica alude como elemento de clasificación del nuevo grupo B. Y, todo ello, en virtud de estas mismas disposiciones básicas que, al respecto, se contienen en el artículo 76 del TREBEP y el artículo 19 apartados 5, 6 y 11 de la Ley 48/2015, de 29 de octubre, de Presupuestos Generales del Estado para el año 2016 ${ }^{27}$. Añádase al anterior aparato legislativo lo dispuesto por los artículos 167 del TRRL, y si seguimos las referencias legislativas a la Comunidad de Madrid, respecto a esta cuestión, el artículo 107.4 de la Ley 2/2003, de 11 de marzo,

\footnotetext{
22 STC 172/1996, de 31 de octubre de 1996, Pleno, conflicto positivo de competencia, núm. 407/86.

23 STC 1/2003, de 16 de enero, Pleno, Recurso de inconstitucionalidad 2987/95.

24 STC 182/1988, de 13 de octubre, Pleno, conflicto positivo de competencia, núm. 402/1984.

25 STC 172/1996, de 31 de octubre, Pleno, conflicto positivo de competencia, núm. 407/86.

26 STC 197/1996, de 28 de noviembre, Pleno, recurso de inconstitucionalidad, núm. 847/93.

27 Y que también se repite en la Ley 3/2017, de 27 de junio, de Presupuestos Generales del Estado para el año 2017.
} 
REALA. Nueva Época - N. 10, Octubre 2018 - ISSN: 1989-8975 - DOI: 10.24965/reala.v0i10.10514 - [Págs. 96-108]

Sobre la aplicabilidad del grupo B del artículo 76 del Texto Refundido del Estatuto Básico del Empleado Público como grupo de ...

Agustín Juan Gil Franco

de Administración Local de la Comunidad de Madrid atribuyen a las Corporaciones locales y el artículo 11.1 p) de la Ley 22/2006, de 4 de julio, de Capitalidad y de Régimen Especial de Madrid. Téngase en cuenta que el único límite impuesto a las corporaciones locales propiciado desde el TRRL, es establecido en el artículo 131 , al determinar que las subescalas, clases y categorías de los funcionarios locales propios han de quedar agrupadas, conforme a la legislación básica del Estado, en los grupos que ésta determine, de acuerdo con la titulación exigida para su ingreso.

Sin embargo, podría señalarse una cierta cortapisa respecto de la efectiva adscripción de categorías funcionariales locales al grupo B, y es que el artículo $3^{28}$ del Real Decreto 861/1986, de 25 de abril, por el que se establece el régimen de las retribuciones de los Funcionarios de Administración Local, -norma dictada desde el fundamento del artículo 93 de la LRBRL-, traslada de forma mimética el sistema de intervalos de los niveles de puestos de trabajo de los funcionarios de Administración Local, los que en cada momento se establezcan para los funcionarios de la Administración del Estado. Lo cual significa que serían directamente aplicables, a los funcionarios propios de las Administraciones locales, las previsiones del artículo 71 del Real Decreto 364/1995, de 10 de marzo, por el que se aprueba el Reglamento General de Ingreso del Personal al servicio de la Administración General del Estado y de Provisión de Puestos de Trabajo y Promoción Profesional de los Funcionarios Civiles de la Administración General del Estado, que establece el sistema de intervalos de niveles de puestos de trabajo correspondientes a cada grupo/subgrupo en el que figuren clasificados los distintos cuerpos/escalas en la Administración General del Estado. Dichos intervalos, como es de general conocimiento, se estructuran de la siguiente manera:

\begin{tabular}{lcc}
\hline Cuerpos o Escalas & Nivel mínimo & Nivel máximo \\
\hline Grupo A (ahora subgrupo A1) & 20 & 30 \\
\hline Grupo B (ahora subgrupo A2) & 16 & 26 \\
\hline Grupo C (ahora subgrupo C1) & 11 & 22 \\
\hline Grupo D (ahora subgrupo C2) & 9 & 18 \\
\hline Grupo E (ahora agrup. prof.) & 7 & 14 \\
\hline
\end{tabular}

Traslación de sus efectos al ámbito local que no se compadece con el supuesto carácter supletorio de dicho Real Decreto 364/1995. Decreto que, a pesar de su praxis generalizada en las distintas Administraciones públicas, no tiene carácter de básico tal y como se confirma a través de su artículo 1.3.

Como puede observarse dicho sistema de intervalos de niveles de los distintos grupos, -ahora subgrupos tras la Disposición Transitoria $3 .^{a}$ del TREBEP-, no contempla la novedad legislativa básica del artículo 76 del TREBEP en relación con la creación de un nuevo grupo B, para el que no se establece disposición alguna al respecto. Ciertamente este puede calificarse como de elemento adverso en cuanto a las posibilidades de «activación» del grupo B en el ámbito local, mediante la creación de escalas y categorías funcionariales a adscribir directamente al mismo.

A pesar de esta objeción, y con ello volvemos al principio, a nuestro juicio, parece dudoso el carácter básico que pueda darse precisamente, a los tres primeros apartados del artículo 3 del Real Decreto 861/1986, de 25 de abril, por el que se establece el régimen de las retribuciones de los Funcionarios de Administración Local, a pesar de la declaración efectuada por su propio texto. En efecto, el artículo 93 de la LRBRL, establece que:

${ }^{28} \mathrm{El}$ artículo en su integridad es el que se detalla a continuación: "1. Los intervalos de los niveles de puestos de trabajo de los funcionarios de Administración Local serán los que en cada momento se establezcan para los funcionarios de la Administración del Estado. 2. Dentro de los límites máximo y mínimo señalados, el Pleno de la Corporación asignará nivel a cada puesto de trabajo atendiendo a criterios de especialización, responsabilidad, competencia y mando, así como a la complejidad territorial y funcional de los servicios en que esté situado el puesto. 3. En ningún caso los funcionarios de Administración Local podrán obtener puestos de trabajo no incluidos en los niveles del intervalo correspondiente al grupo de titulación en que figure clasificada su Escala, Subescala, clase o categoría. 4. Los complementos de destino asignados por la Corporación deberán figurar en el presupuesto anual de la misma con la cuantía que establezca la Ley de Presupuestos Generales del Estado para cada nivel. 5. Los funcionarios sólo podrán consolidar grados incluidos en el intervalo correspondiente al grupo en que figure clasificada su Escala, Subescala, clase o categoría, de conformidad con lo establecido en el artículo 21 de la Ley de Medidas para la reforma de la Función Pública, y de acuerdo con lo establecido en el presente Real Decreto.». 
REALA. Nueva Época - N.o 10, Octubre 2018 - ISSN: 1989-8975 - DOI: 10.24965/reala.v0i10.10514 - [Págs. 96-108]

Sobre la aplicabilidad del grupo B del artículo 76 del Texto Refundido del Estatuto Básico del Empleado Público como grupo de ...

Agustín Juan Gil Franco

«1. Las retribuciones básicas de los funcionarios locales tendrán la misma estructura e idéntica cuantía que las establecidas con carácter general para toda la función pública.

2. Las retribuciones complementarias se atendrán, asimismo, a la estructura y criterios de valoración objetiva de las del resto de los funcionarios públicos. Su cuantía global será fijada por el Pleno de la Corporación dentro de los límites máximos y mínimos que se señalen por el Estado.

3. Las Corporaciones locales reflejarán anualmente en sus Presupuestos la cuantía de las retribuciones de sus funcionarios en los términos previstos en la legislación básica sobre función pública».

Por tanto, no es difícil deducir el dudoso encaje de algunos de los preceptos del artículo 3 del Real Decreto sobre los propios mandatos básicos del artículo 93 LRBRL que tan sólo vienen a referirse sobre el régimen retributivo y no sobre la carrera profesional de los funcionarios locales. Aspecto este último que debe verse modulado de forma clara por las disposiciones contenidas en el TREBEP, en sus artículos 22 a 24; Téngase en cuenta que el legislador básico local se refiere de forma indeterminada respecto de la «carrera profesional» con una previsión podríamos decir «del todo básica» al señalar que el sistema retributivo debe responder a una "estructura y criterios de valoración objetiva de las del resto de los funcionarios públicos». Afirmación que no implica que la legislación de desarrollo (o la acción normativa de la Ordenanza/reglamento local) deba establecer una opción exclusiva de carrera profesional, cuando precisamente el TREBEP abre a las Comunidades Autónomas la posibilidad de regular la "propia» carrera profesional de sus funcionarios como también esta opción es claramente extensible a una carrera administrativa singular en el ámbito local. Es, pues, francamente discutible -y volvemos repetirlo- que, por un lado, el artículo 93 de la LRBRL faculte al Real Decreto 861/1986, de 25 de abril, por el que se establece el régimen de las retribuciones de los Funcionarios de Administración Local, para regular y establecer el sistema de carrera profesional de los funcionarios propios locales cuando la ley básica local tan sólo viene a referirse a las estructuras retributivas generales, en la división, ya clásica y general, de «básicas» y "complementarias», junto a la desagregación de cada uno de los mismos en los distintos componentes. Es decir, que la determinación de la existencia de un complemento de destino y lo que se retribuye por ello no implica -ni en nuestra opinión debe implicar- la generación indirecta de un sistema de carrera profesional determinado y cerrado, máxime cuando la propia LRBRL no hace referencia alguna a esta cuestión, y el TREBEP se remite para ello a «las leyes de Función Pública que se dicten en desarrollo de este Estatuto [que] regularán la carrera profesional aplicable en cada ámbito», como oportunamente señala el apartado 3 del artículo 16.

Es del todo incontestable la clara amplitud en la decisión del modelo de carrera y sus contenidos que el TREBEP da a cada Administración, a través de los artículos 16 y 17 del mismo. En este sentido el Tribunal Constitucional, en su STC 130/2013 ${ }^{29}$, ha señalado que «ciertamente, (...) no cabe atribuir a las bases estatales la misma extensión e intensidad cuando se refieren a aspectos meramente organizativos internos que no afectan directamente a la actividad externa de la Administración y a los administrados, que en aquellos aspectos en los que se da esta afectación» (STC 50/1999, FJ 3)». De ahí que estos tres primeros apartados, -junto al 5-, del artículo 3 del mencionado Real Decreto 861/1986, de 25 de abril, carecerían del carácter básico «ex artículo 93 de la LRBRL», si nos atenemos a la trasformación legislativa operada en esta materia. De igual forma, dichos apartados, vendrían a contradecir el sistema competencial establecido para la regulación de personal funcionario de las Entidades Locales, que se preceptúa en el artículo 3.1 ya que: "el personal funcionario de las entidades locales se rige por la legislación estatal que resulte de aplicación, de la que forma parte este Estatuto y por la legislación de las comunidades autónomas, con respeto a la autonomía local».

Visto lo expuesto, la cuestión a dilucidar finalmente es, si las Corporaciones locales podrían establecer el sistema de carrera y promoción profesional de este tipo de funcionarios propios, adscritos al grupo $\mathrm{B}$, a pesar de lo establecido por el artículo 3 del Real Decreto 861/1986, de 25 de abril, y dada la inexistencia de intervalos de niveles precisamente para este grupo B en la legislación de la Administración General del Estado. A nuestro entender y sobre las bases de los artículos 16 y 17 del TREBEP y el sistema de fuentes establecido por el artículo 3.1 del mismo, y ante la inexistencia de legislación autonómica al respecto, las Corporaciones locales podrían estar capacitadas para regular el sistema de carrera del grupo $\mathrm{B}$, máxime

29 STC 130/2013, de 4 de junio. Recurso, núm. 931/2004. 
REALA. Nueva Época - N.o 10, Octubre 2018 - ISSN: 1989-8975 - DOI: 10.24965/reala.v0i10.10514 - [Págs. 96-108]

Sobre la aplicabilidad del grupo B del artículo 76 del Texto Refundido del Estatuto Básico del Empleado Público como grupo de ...

Agustín Juan Gil Franco

si tenemos en cuenta la apreciación no básica de los cuatro apartados del artículo 3 del Real Decreto $861 / 1986$, de 25 de abril.

En principio, podría argumentarse que el tenor literal del artículo 3 el Real Decreto 861/1986, de 25 de abril, en la redacción dada por el del Real Decreto 158/1996, de 2 de febrero, no deja lugar a dudas en cuanto a la aplicación de los intervalos de niveles a los funcionarios propios de la Administración local de los establecidos para los funcionarios de la $\mathrm{AGE}^{30}$, pero la realidad es que la Administración General del Estado, aun estableciendo los elementos básicos del grupo B del artículo 76 del EBEP, no ha determinado el sistema del intervalo de niveles del mismo, tal vez conscientes de no ser una norma o disposición con características básicas, dada su indudable conexión con la organización propia de cada Administración pública. Aspecto este que ha sido reconocido claramente por los artículos 16 y 17 del TREBEP, en los que hay una remisión inmediata a las leyes de función pública correspondientes. Téngase en cuenta que los mismos se refieren de forma directa a la carrera profesional de los funcionarios públicos. Sea lo que fuere, dicha ausencia normativa no ha supuesto inconveniente para algunos Ayuntamientos que han creado, tanto categorías funcionariales específicas, con los contornos de funciones y atribuciones ligadas a actividades profesionales determinadas y ser clasificadas en el nuevo grupo B, como para determinar su propia carrera dentro de unos intervalos máximos y mínimos de los niveles, en el desempeño de estos puestos de trabajo. Es el caso, por ejemplo, de los Ayuntamientos de Alicante, Segovia o A Coruña los cuales han creado categorías funcionariales y puestos de trabajo adscritos a dicho grupo ${ }^{31}$.

Esto no es sino una prueba más de que la lejanía de aprobación del Real Decreto de retribuciones arriba mencionado, incluso de su modificación posterior en 1996, y la entrada en vigor del Estatuto Básico del Empleado Público en 2007, hacen que no sea incompatible con las disposiciones legislativas básicas, que los Ayuntamientos establezcan categorías de funcionarios que recojan como requisito de acceso la titulación académica oficial de Técnico superior en formación profesional -y por ende clasificarlas en el grupo B-, y junto a ello, la asignación de niveles (complemento de destino) a los puestos de trabajo que sean explícitamente diseñados para funcionarios de dicho grupo clasificatorio. Y ello, con razón máxima cuando la ley de función pública autonómica correspondiente haya podido prescindir de la regulación de dicho grupo de clasificación. Esta actuación local es plenamente subsumible en el inciso final del artículo 3 del TREBEP sobre el sistema de fuentes en relación con el personal funcionario de las Entidades Locales, del que se predica un claro y conceptual respeto a la autonomía local.

\section{CONCLUSIONES}

De lo expuesto hay un suficiente grado de regulación legal como para advertir que el grupo $B$, como no podía ser de otra manera, tiene un predicamento administrativo real y es de aplicación inmediata. A veces, y ello es una actitud de los gestores públicos, parece que el carácter básico de las disposiciones referentes al referido grupo B, parecería que las sustrae de su aplicabilidad directa, predicando un la necesidad de su «desarrollo» por vías legislativas. Todo lo contrario, la legislación básica despliega todos sus efectos y ella misma determina, si ello fuera procedente, el ámbito suspensivo de los mismos. Precisamente todo lo que supone el concepto y razón de la legislación básica es expresión de la «certidumbre jurídica». Es más, ante la inactividad legislativa/normativa al respecto, cabe la acción normativa de las Corporaciones locales desde la fórmula habilitante del inciso final ex artículo 3 del EBEP «con respeto a la autonomía local». Este inciso es además es una cláusula de garantía en cuanto al modelo de función pública propio que pudieran establecer las distintas corporaciones locales y supone una manifestación clara de su potestad de organización propia.

30 «Los intervalos de los niveles de puestos de trabajo de los funcionarios de Administración Local serán los que en cada momento se establezcan para los funcionarios de la Administración del Estado. Dentro de los límites máximo y mínimo señalados, el Pleno de la Corporación asignará nivel a cada puesto de trabajo atendiendo a criterios de especialización, responsabilidad, competencia y mando, así como a la complejidad territorial y funcional de los servicios en que esté situado el puesto».

31 En efecto, en el Ayuntamiento de Alicante, ha tenido reflejo lo expresado en la RPT, aprobada por la Junta de Gobierno Local de fecha 5-12-2016) (BOP núm. 243 de 21-12-2016) ligado al servicio de Prevención y Extinción de incendios y salvamento, en el que todos los puestos se clasifican dentro del grupo B y con un intervalo de niveles entre el 20 y el 24 . En el Ayuntamiento de Segovia, figuran en la plantilla presupuestaria, 4 puestos de Técnicos «B», y en la RPT de fecha 1-1-2017, se reflejan los puestos de «Técnico B informática NCD 20» «Técnico de medio ambiente NCD 20» y «Técnico de obra civil NCD 20». Y otro tanto podemos decir del Ayuntamiento de A Coruña en cuya RPT de 2017, figuran los puestos de «Técnico en tratamiento en Informático NCD 21 »; «Delineante» o «Jefe de Delineación» con un NCD 20 y 21 respectivamente, también el puesto de «Inspector de Medio Ambiente NCD 20 » «Integrador social NCD 20» y «Animador socio cultural NCD 20». Todos reservados en exclusiva al nuevo grupo B. 
REALA. Nueva Época - N.o 10, Octubre 2018 - ISSN: 1989-8975 - DOI: 10.24965/reala.v0i10.10514 - [Págs. 96-108]

Sobre la aplicabilidad del grupo B del artículo 76 del Texto Refundido del Estatuto Básico del Empleado Público como grupo de ...

Agustín Juan Gil Franco

Puede afirmarse, sin lugar a duda alguna, que las potestades de ordenación de las categorías de funcionarios locales propios, -entre las que podemos incluir la clasificación, y siempre dentro de los contornos básicos de la cuestión-, es una facultad propiamente local, ínsita en su autonomía, y por tanto, con perfiles netamente abiertos a una regulación propia. Por tanto, los Ayuntamientos y también la Diputaciones provinciales pueden crear categorías funcionariales de adscripción directa al grupo B.

\section{BIBLIOGRAFIA}

CASTILLO BLANCO, F. A. y SÁNCHEZ MORÓN, M. (2008): Comentarios a la Ley del estatuto básico del empleado público. Lex Nova.

DEL REY GUANTER, S. (2008): Comentarios al Estatuto básico del empleado público. La Ley.

FUENTETAJA PASTOR, J. A. (2007): "El Estatuto Básico del Empleado Público", en Revista de Administración Pública, núm. 174.

FUENTETAJA PASTOR, J. A. (2010): "Función pública local", en FUENTETAJA PASTOR, J. A. y FERNÁNDEZ RODRÍGUEZ, C., Manual de Derecho local, Madrid, lustel (1. ${ }^{a}$ edición).

FUENTETAJA PASTOR, J. A. y PARADA VÁZQUEZ, J. R. (2017): Derecho de la Función Pública. Aranzadi. Thomson Reuters.

JIMÉNEZ ASENSIO, R. y CASTILLO BLANCO, F. A. (2009): Informe sobre el empleo público local: balance y propuestas para su racionalización en el marco de la reforma del empleo público. Fundación Democracia y Gobierno Local.

PALOMAR OlmedA, A. (2016): Derecho de la Función Pública. Régimen jurídico de los funcionarios públicos. Dykinson S. L.

PALOMAR OLMEDA, A., SEMPERE NAVARRO, A. (dirs.), QUINTANILLA NAVARRO, R. Y. (coord.) (2008): Comentarios a La Ley 7/2007, de 12 de abril, del Estatuto Básico del Empleado Público. Aranzadi.

SÁNCHEZ MORÓN, M. (2017): Derecho de la función pública. Tecnos. 